\title{
HUBUNGAN PENGETAHUAN DENGAN KEPATUHAN DIET PADA PENDERITA DIABETES MELLITUS DI POSYANDU LANSIA CEMPAKA KELURAHAN TEMBOK DUKUH KECAMATAN BUBUTAN SURABAYA
}

\author{
Difran Nobel Bistara ${ }^{1}$, Nur Ainiyah ${ }^{2}$ \\ Universitas Nahdlatul Ulama Surabaya \\ nobel@unusa.ac.id ${ }^{1}$, ainiyahanuri@unusa.ac.id ${ }^{2}$
}

\begin{abstract}
Diabetes mellitus (DM) is a degenerative disease that can be controlled with the four pillars of management. One of the pillars is compliance in the implementation of the diet "3J". This study aims to determine the relationship of knowledge with dietary compliance in patients with DM in Posyandu Lansia Cempaka, Tembok Dukuh, Bubutan, Surabaya. The study design is analytic correlation with approach cross sectional. Sample research is patients with DM in Posyandu Lansia Cempaka the active come Posyandu Lansia of as many as 33 patients. The independent variable is the knowledge of diet DM. The dependent variable is a dietary compliance in patients with DM. Analysis of data using correlation coefficient with somers test. The results showed that people with diabetes who have a good knowledge of most of the diet compliance in the diet is also good. The results of the analysis test Somers obtained $p$ value of 0.000 means that there is a relationship between knowledge and dietary compliance in patients with DM, with level of closeness $0,154(0,00<|r| \leq 0,20)$ with significance of closeness that is very low or very weak. Recommendations on these results in order to develop methods of collecting data through interviews and observations to gain a more realistic picture of the data. Also developed variables that affect the knowledge and compliance such as the characteristics of respondents and family support.
\end{abstract}

ABSTRAK: Penyakit Diabetes Melitus (DM) merupakan penyakit degeneratif yang dapat dikendalikan dengan empat pilar penatalaksanaan. Salah satu pilar adalah kepatuhan dalam pelaksanaan diet "3J". Penelitian ini bertujuan mengetahui hubungan pengetahuan dengan kepatuhan diet pada penderita DM di Posyandu Lansia Cempaka, Tembok Dukuh, Bubutan, Surabaya. Rancangan penelitian secara analitik korelasi dengan pendekatan cross sectional. Sample penelitian adalah penderita DM di Posyandu Lansia Cempaka yang aktif datang kegiatan posyandu lansia sebanyak 33 penderita. Variabel bebas adalah pengetahuan tentang diet DM. Variabel terikat adalah kepatuhan diet pada penderita DM. Analisis data menggunakan koefisien korelasi dengan uji somers. Hasil penelitian menunjukan bahwa penderita DM yang memiliki pengetahuan diet baik sebagian besar kepatuhan dalam menjalankan diet juga baik. Hasil analisis uji Somers didapatkan $p$-value sebesar 0,000 artinya terdapat hubungan antara pengetahuan dengan kepatuhan diet pada penderita DM, tingkat keeratan $0,154(0,00<|\mathrm{r}| \leq 0,20)$ dengan kemaknaan keeratan sangat rendah atau lemah sekali. Rekomendasi hasil penelitian ini agar dikembangkan metode pengumpulan data melalui wawancara dan observasi untuk mendapatkan gambaran data yang lebih nyata. Juga dikembangkan variabel yang mempengaruhi pengetahuan dan kepatuhan seperti karakteristik responden dan dukungan keluarga.

Kata kunci: Pengetahuan, Kepatuhan, Diet Diabetes Mellitus 


\section{PENDAHULUAN}

Diabetes Melitus (DM) merupakan penyakit menahun yang ditandai dengan kadar glukosa darah melebihi normal (International Diabetes Federation atau IDF, 2015). Penyakit ini ditandai dengan hiperglikemi akibat kelainan kerja pada insulin, sehingga terjadi penumpukan karbohidrat dalam bentuk glukosa yang mengakibatkan peningkatan gula dalam darah (Smeltzer \& Bare, 2010; PERKENI 2011).

Prevalensi DM di seluruh dunia, tercatat sebesar 382 juta orang berumur 40-59 tahun dan diperkirakan akan terus meningkat setiap tahunnya (IDF, 2015). Indonesia merupakan Negara ke tujuh terbesar untuk prevalensi diabetes melitus. Hasil survei World Health Organization (WHO) tahun 2011 menyatakan bahwa jumlah penderita DM di Indonesia adalah 8,5 juta jiwa setelah China (98,4 juta), India $(65,1$ juta), Amerika Serikat (24,4 juta), Brazil (11,9 juta), Russian (10,9 juta) dan Mexico (8,7 juta) dan diperkirakan tahun 2035 prevalensi penyakit DM di Indonesia meningkat menjadi 14,1 juta jiwa (PERKENI, 2011; IDF, 2015).

Penyakit DM ini dapat dikendalikan dengan pilar penatalaksanaan DM melalui edukasi kepada penderita dan keluarga. Topik edukasi seperti pemahaman tentang pengertian DM, tanda dan gejala, cara mencegah komplikasi, latihan fisik seperti olahraga (frekuensi, intensitas, time dan tipe olah raga), minum obat sesuai resep dokter dan kepatuhan dalam pelaksanaan diet “3J" meliputi jadual, jumlah dan jenis (Kemenkes RI, 2013).

Kepatuhan diet penderita DM menjadi salah satu hal penting dalam penatalaksanaan karena seringkali penderita tidak memperhatikan asupan makanan yang seimbang. Diet yang tepat dapat membantu mengontrol kadar gula dalam darah, mengingat bahwa meningkatnya gula darah menjadi penyebab ketidakseimbangan jumlah insulin (Niven, 2010).

Hasil penelitian yang dilakukan oleh Hassan dkk (2013) terhadap 36 penderita DM sebagian besar (55,6\%) tidak patuh terhadap diet. Penelitian lain yang dilakukan oleh Phitri (2013) pada 54 penderita DM di RSUD AM. Parikesit Kalimantan Timur didapatkan hasil sebagian besar $(57,4 \%)$ tidak patuh terhadap diet. Hasil Penelitian tersebut di atas menunjukkan bahwa kepatuhan diet penderita DM sebagian besar dalam kategori kurang. Oleh karena itu pentingnya pengetahuan tentang diet dan motivasi terhadap kepatuhan penerapan diet. Penderita DM yang patuh terhadap diet maka kadar gula darah dalam rentang normal, mengurangi dampak komplikasi dan kualitas hidup lebih baik (Purwitaningtyas et al, 2015).

Komplikasi yang sering dialami oleh penderita DM antara lain stroke dengan prevalensi 5,30\%, ulkus kaki $8,70 \%$, kebutaan $1-2 \%$, penyakit ginjal $20 \%$, gagal jantung $2,70 \%$, neuropati $54,00 \%$ dan bahkan $50 \%$ mengalami kematian (Kemenkes RI, 2013; Smeltzer \& Bare, 2010). Komplikasi tersebut dapat dicegah bila penderita DM patuh menjalani diet. Penyebab penderita tidak patuh dalam menjalani diet karena tidak memahami manfaat diet (Reach, 2011). Oleh karena itu pengetahuan tentang diet DM berperan penting dalam proses pembentukan perilaku berupa kepatuhan menjalankan diet pada penderita DM (Kemenkes, 2013; Phitri, 2013).

Penelitian ini bertujuan untuk mengetahui hubungan pengetahuan dengan kepatuhan penerapan diet pada penderita DM di Posyandu Lansia Cempaka, Tembok Dukuh, Bubutan, Surabaya.

\section{METODE}




\begin{tabular}{|c|}
\hline $\begin{array}{ccc}\text { Karakteristik } & \text { Frekuensi } & \text { Persentase } \\
\text { Responden } & (f) & (\%) \\
\end{array}$ \\
\hline Umur \\
\hline $30-45$ \\
\hline $46-55$ \\
\hline $56-65$ \\
\hline 23,3 \\
\hline Total \\
\hline $\begin{array}{l}\text { Jenis } \\
\text { Kelamin }\end{array}$ \\
\hline Laki-laki \\
\hline Perempuan \\
\hline Total \\
\hline Pendidikan \\
\hline SD \\
\hline SMP \\
\hline SMA \\
\hline $\begin{array}{l}\text { Perguruan } \\
\text { Tinggi }\end{array}$ \\
\hline Total \\
\hline Pekerjaan \\
\hline PNS \\
\hline Tidak bekerja \\
\hline Wiraswasta \\
\hline $\begin{array}{lll}\text { Total } & 30 & 100,0 \\
\end{array}$ \\
\hline $\begin{array}{l}\text { Penelitian jenis } \\
\text { menggunakan rancangan analititik } \\
\text { korelasi dengan pendekatan cross } \\
\text { sectional. Sampel penelitian ini adalah } \\
\text { penderita DM di Posyandu Lansia } \\
\text { Cempaka berjumlah } 33 \text { orang. Tehnik } \\
\text { sampling adalah purposive sampling. } \\
\text { Variabel bebas adalah pengetahuan diet } \\
\text { penderita DM. Variabel terikatnya } \\
\text { adalah kepatuhan penerapan diet pada } \\
\text { penderita DM. Analisis data secara } \\
\text { deskriptif dan analitik menggunakan } \\
\text { koefisien korelasi dengan uji somers. }\end{array}$ \\
\hline
\end{tabular}

\section{HASIL DAN PEMBAHASAN}

\section{Karakteristik Respoden}

Karakteristik responden dalam penelitian ini meliputi umur, jenis kelamin, pendidikan dan pekerjaan. Distribusi frekuensi responden hasil penelitian dapat dilihat pada table berikut:
Tabel 1. Distribusi Frekuensi Karakteristik Penderita DM di Posyandu Lansia "Cempaka" Tembok Dukuh Bubutan Surabaya, bulan Februari 2017 $(n=30)$

Tabel 1 menunjukkan bahwa sebanyak $40 \%$ penderita DM berumur 36-45 tahun, sebagian besar (56,7 \%) perempuan, berpendidikan SMA sejumlah $40 \%$, dan sebagian besar $(53,3$ $\%$ ) bekerja wiraswasta.

\section{Pengetahuan Diet DM}

Data pengetahuan diet DM pada penderita DM di Posyandu Lansia Cempaka, Tembok Dukuh, Bubutan, Surabaya dapat dilihat pada tabel 2.

Tabel 2. Distribusi Frekuensi Pengetahuan diet pada penderita DM di Posyandu Lansia "Cempaka" Tembok Dukuh Bubutan Surabaya, bulan Februari $2017(\mathrm{n}=30)$

\begin{tabular}{lcc}
\hline $\begin{array}{c}\text { Kategori } \\
\text { Pengetahuan } \\
\text { Diet DM }\end{array}$ & $\begin{array}{c}\text { Frekuensi } \\
\text { (f) }\end{array}$ & $\begin{array}{c}\text { Persentase } \\
\mathbf{( \% )}\end{array}$ \\
\hline Baik & 20 & 66,7 \\
Kurang & 10 & 33,3 \\
\hline Total & $\mathbf{3 0}$ & $\mathbf{1 0 0 , 0}$ \\
\hline
\end{tabular}

Tabel 2 menunjukkan bahwa sebagian besar $(66,7 \%)$ penderita DM memiliki pengetahuan baik.

\section{Kepatuhan diet DM}

Data kepatuhan diet penderita DM di Posyandu Lansia Cempaka, Tembok Dukuh, Bubutan, Surabaya dapat dilihat pada tabel 3.

Tabel 3. Distribusi Frekuensi Kepatuhan

Diet penderita DM di Posyandu Lansia "Cempaka" Tembok Dukuh Bubutan Surabaya, bulan Februari 2017 $(\mathrm{n}=30)$

\begin{tabular}{ccc}
\hline Kategori & $\begin{array}{c}\text { Frekuensi } \\
\text { Kepatuhan } \\
\text { Diet }\end{array}$ & $\begin{array}{c}\text { Persentase } \\
(\%)\end{array}$ \\
\hline
\end{tabular}




\begin{tabular}{lcc}
\hline $\begin{array}{c}\text { Penderita } \\
\text { DM }\end{array}$ & & \\
\hline Baik & 16 & 53,3 \\
Buruk & 14 & 46,7 \\
\hline Total & $\mathbf{3 0}$ & $\mathbf{1 0 0 , 0}$ \\
\hline
\end{tabular}

Tabel 3 menunjukkan bahwa kepatuhan diet penderita DM sebagian besar $(53,3 \%)$ baik.

\section{Analisis Bivariat}

Analisis bivariat pada variabel pengetahuan diet DM dengan kepatuhan diet DM menggunakan uji sommers.

Tabel 4. Tabulasi Silang Hubungan Pengetahuan dengan Kepatuhan Diet Pada Penderita DM di Posyandu Lansia "Cempaka" Tembok Dukuh Bubutan Surabaya, bulan Februari 2017 ( $\mathrm{n}=30)$

\begin{tabular}{|c|c|c|c|c|c|c|c|c|}
\hline \multirow{3}{*}{$\begin{array}{c}\text { Peng } \\
\text { etahu } \\
\text { an } \\
\text { diet } \\
\text { DM }\end{array}$} & \multicolumn{7}{|c|}{ Kepatuhan diet DM } & \multirow[t]{3}{*}{$P$} \\
\hline & \multicolumn{2}{|c|}{ Baik } & \multicolumn{2}{|c|}{$\begin{array}{l}\text { Kur } \\
\text { ang }\end{array}$} & \multicolumn{2}{|c|}{$\begin{array}{c}\text { Tota } \\
\text { I }\end{array}$} & & \\
\hline & $\mathbf{F}$ & $\%$ & $\mathbf{F}$ & $\%$ & $\mathbf{F}$ & $\%$ & $r$ & \\
\hline Baik & 1 & 4 & 8 & 2 & 2 & 6 & 0,1 & 0,0 \\
\hline & 2 & 0 & & $\begin{array}{l}6 \\
7\end{array}$ & 0 & $\begin{array}{c}6, \\
7\end{array}$ & 54 & 00 \\
\hline Buru & 4 & 1 & 6 & 2 & 1 & 3 & & \\
\hline $\mathrm{k}$ & & $\begin{array}{l}3, \\
3\end{array}$ & & 0 & 0 & $\begin{array}{c}3, \\
3\end{array}$ & & \\
\hline Total & $\begin{array}{l}1 \\
6\end{array}$ & $\begin{array}{l}5 \\
3, \\
3\end{array}$ & $\begin{array}{l}1 \\
4\end{array}$ & $\begin{array}{l}4 \\
6, \\
7\end{array}$ & $\begin{array}{l}3 \\
0\end{array}$ & $\begin{array}{l}1 \\
0 \\
0\end{array}$ & & \\
\hline
\end{tabular}

Tabel 4 menunjukan bahwa penderita DM yang memiliki pengetahuan diet baik sebagian besar kepatuhan diet nya juga baik. Hasil analisis didapatkan $p$-value 0,000 artinya ada hubungan antara pengetahuan dengan kepatuhan diet pada penderita DM, dengan tingkat keeratan 0,154 $(0,00<|r| \leq 0,20)$ yang menunjukkan sangat rendah atau lemah sekali.

\section{PEMBAHASAN}

\section{Pengetahuan diet pada penderita DM}

Tabel 1 menunjukan bahwa dari 30 penderita DM sebagian besar pengetahuannya baik tentang diet DM. Pengetahuan tersebut berkaitan dengan penatalaksanaan DM meliputi keterlibatan dalam kegiatan penyuluhan, melakukan latihan fisik atau olah raga, pengobatan, dan diet " $3 \mathrm{~J}$ " yang terdiri dari jenis makanan, jumlah dan jadwal makan serta komplikasi DM. Pengetahuan tersebut diharapkan dapat diimplementasikan dalam kehidupan sehari-hari bagi penderita DM sehingga penderita DM dapat mengatasi bila ada gejala dan keluhan, mempertahankan rasa nyaman, pengendalian gula darah dan mencegah komplikasi.

Pengetahuan tentang penatalaksanaan DM bagi penderita DM merupakan salah satu faktor penting terbentuknya perilaku kepatuhan. Pengetahuan adalah seluruh konsep, gagasan, ide, kemampuan yang dimiliki seseorang dan diungkapkan dalam bentuk jawaban baik lisan maupun tertulis (Gultom, 2012; Bloom, 1956). Dengan memiliki ide, gagasan dan kemampuan maka penderita DM dapat mengembangkan perilaku hidup sehat dan terbebas dari komplikasi penyakit DM (Magurova et al, 2012).

Hasil penelitian ini sejalan dengan penelitian yang dilakukan oleh Hassan (2013), di RSUD Dr. Zainoel Abidin Banda Aceh kepada 91 penderita DM didapatkan bahwa pengetahuan tentang diet DM sebagian besar $(73,6 \%)$ baik. Penelitian lain yang dilakukan oleh Reach (2011) di Desa Gonilan kepada 45 penderita DM didapatkan hasil sebagian $(42,2 \%)$ pengetahuannya baik.

\section{Kepatuhan diet pada penderita DM} Tabel 2 menunjukan bahwa kepatuhan penderita DM dalam menjalankan diet sebagian adalah baik. 
Kepatuhan diet DM mengandung arti bahwa penderita telah mengambil keputusan, meyakini dan menjalankan rekomendasi diet DM yang diberikan oleh petugas kesehatan (Niven, 2010; Hassan, 2013).

Rekomendasi yang diberikan oleh petugas kesehatan dalam hal ini ahli gizi difokuskan pada pengaturan jenis makanan, jumlah dan jadwal makan dalam rangka untuk menurunkan kadar gula darah.

Hasil penelitian ini sejalan dengan penelitian yang dilakukan oleh Lestari (2012) di RSUP Fatmawati terhadap 100 penderita DM rawat jalan, didapatkan sebagian penderita DM patuh menjalankan diet (58\%). Penelitian lain yang dilakukan oleh Reach (2011) di Desa Gonilan pada 45 penderita DM didapatkan sebagian patuh (48,9\%).

\section{Hubungan pengetahuan dengan kepatuhan diet pada penderita DM}

Hasil penelitian ini menunjukan bahwa penderita DM di Posyandu Lansia Cempaka yang memiliki pengetahuan diet DM baik juga memiliki kepatuhan yang baik, sebaliknya penderita DM yang memiliki pengetahuan kurang cenderung kepatuhannya lebih rendah. Hasil analisis diperoleh $p$-value sebesar 0,000 yang menunjukkan bahwa ada hubungan signifikan antara pengetahuan diet DM dengan kepatuhan diet DM. Kemaknaan keeratan sangat rendah atau lemah sekali yang artinya apabila penderita DM mempunyai pengetahuan baik maka akan mempengaruhi kepatuhan diet penderita DM. Hal itu sesuai dengan konsep perilaku yang menyatakan bahwa perilaku akan lebih menetap bila didasari oleh pengetahuan sehingga memiliki kesadaran untuk bertindak (Hassan, 2013; Lestari, 2012; Gultom, 2012). Niven (2010) juga menjelaskan bahwa penderita yang mengidap suatu penyakit dengan pengetahuan kurang akan menyebabkan penderita tidak patuh dalam menjalankan rekomendasi dari tenaga kesehatan.

Pengetahuan juga dipengaruhi oleh pengalaman, lingkungan dan sosial budaya. Pengalaman diperoleh dipersepsikan, diyakini, sehingga menimbulkan motivasi, niat untuk bertindak dan akhirnya menjadi perilaku (Hassan, 2013). Penderita diabetes yang memiliki pengetahuan baik serta memiliki sikap positif dapat mencegah komplikasi penyakit DM (Garcia- Perez et al, 2013). Oleh karena itu pengetahuan terhadap diet diabetes sangat penting untuk kedisiplinan dalam menjalankan pola hidup sehat dan terbebas dari komplikasi (Gultom, 2012; Magurova et al, 2012).

Penderita DM yang memiliki pengetahuan kurang tentang diet DM menjadi faktor penghambat menuju perilaku kepatuhan dan sulit mengikuti anjuran dari petugas kesehatan(Gultom, 2012). Odili et al (2011) menjelaskan bahwa pengetahuan mengenai manajemen diabetes merupakan komponen yang dibutuhkan untuk memperoleh kesuksesan dalam pengelolaan diabetes. Demikian pula yang dijelaskan oleh Bloom (1956) bahwa pengetahuan menjadi mediator bagi seseorang untuk melakukan tindakan.

Hasil penelitian ini sejalan dengan penelitian yang dilakukan Odili (2011) di RS Stella Maris Makasar yang menjelaskan bahwa ada hubungan antara pengetahuan dengan kepatuhan dalam menjalani diet dengan nilai keeratan hubungan ditunjukan oleh $p$ value sebesar $0,009(<0,05)$.

\section{SIMPULAN \& SARAN Simpulan}

Hasil penelitian ini menunjukan bahwa ada hubungan antara pengetahuan dengan kepatuhan dalam menjalankan diet pada penderita DM di Posyandu 
Lansia Cempaka Tembok Dukuh Bubutan Surabaya. Hal itu berarti bahwa bila penderita DM memiliki pengetahuan yang baik tentang pengelolaan diet DM maka diikuti dengan kepatuhan dalam menjalankan diet.

\section{Saran}

Rekomendasi dari hasil penelitian ini agar dikembangkan metode pengumpulan data melalui wawancara dan observasi untuk mendapatkan gambaran data yang lebih nyata. Di samping itu juga dapat dikembangkan faktor lain yang mempengaruhi pengetahuan meliputi umur, jenis kelamin, pendidikan dan pekerjaan. Juga faktor dukungan keluarga yang mempengaruhi kepatuhan.

\section{DAFTAR PUSTAKA}

International Diabetes Federation, 2015. IDF Diabetes Atlas. Edisi keenam diakses 24 Agustus 2016 dari $\mathrm{http} / \mathrm{www}$. idf.org/diabetesatlas/5e/t he-global-burden.

Smeltzer \& Bare. (2010). Textbook of medical surgical nursing. Philadelphia: Linppincott.

PERKENI. (2011). Konsensus Pengelolaan dan Pencegahan DM Tipe 2 di Indonesia. Jakarta: PB Perkeni

World Health Organization. (2011). Definition, Diagnosis and Classification of Diabetes Mellitus and Its Complications. Report a WHO Consultation, WHO, Geneva diakses 7 Agustus 2016 dari https://www.idf.org

Kementerian Kesehatan. (2013) Situasi dan Analisis Diabetes

Niven, N. (2010). Psikologi Kesehatan. Jakarta : EGC

Hassan, H.A., Tohid, H., Amin, R.M., Bidin, M.B.L., Muthupalaniappen, L., Omar, K. (2013). Factors Influencing Insulin Acceptance
Among Type 2 Diabetes Mellitus Patients In A Primary Care Clinic: A Qualitative Exploration. BMC Family Practice, 14:164. Diakses tanggal 5 Desember 2015. http://www.biomedcentral.com/14 71-2296/14/164

Phitri, E. H., Widiyaningsih. (2013). "Hubungan antara sikap pengetahuan dan sikap penderita Diabetes Mellitus dengan kepatuhan diet Diabetes Mellitus di RSUD AM. Parikesit Kalimantan Timur". Diakses pada $21 \quad$ November 2015.http://jurnal.unimus.ac.id/ind ex.php/JKMB/article/view/941/99 $\underline{3}$

Purwitaningtyas, Y. Z., Putra, A. E. I. W. G., Wirawan, D.N. (2015). "Faktor Risiko Kendali Glikemik Buruk pada Penderita Diabetes Mellitus Tipe 2 di puskesmas Kembiritan Kabupaten Banyuwangi". Diakses pada 10 Januari 2016. file://C:/Users/M\%20Comp/Down loads/16677-31503-1SM\%20(1).pdf

Reach, Gerard. (2011). Obedience and Motivation as Mechanism for Aderenche to Medication: A Study in Obese Type 2 Diabetic Patient. Patient Preference and Aderenche 2011:5 523-531 diakses pada 24 Desember 2015 dari http://www.ncbi.nlm.nih.gov/PMC /articles/PMC3218113/pdf/ppa-5523.pdf

Gultom, T. Y. (2012). Tingkat Pengetahuan Penderita Diabetes Mellitus Tentang Manajemen Diabetes Mellitus Di Rumah Sakit Pusat Angkatan Darat Gatot Soebroto Jakarta Pusat. Diakses pada 26 Desember 2015. http://lib.ui.ac.id/file?file=digital/2 
0314370-S43834-

Tingkat\%20pengetahuan. FKUI

Garc1'a-Pe'rez, L.E., A'lvarez, M., Dilla, T., Gil-Guille'n, V., OrozcoBeltra'n, D. (2013). Adherence to Therapies in Patients with Type 2 Diabetes. Diabetes Ther 4:175194. Diakses tanggal 24 Agustus 2016.

http://www.ncbi.nlm.nih.gov/pmc/ articles/PMC3889324/pdf/13300 2013 Article 34.pdf

Magurova, D., Majernikova, L., Hloch, S., Tozan, H., Goztepe, K. (2012) Knowledge of diabetes in patients with type 2 diabetes on insulin therapy from eastern Slovakia. Diabetologia Croatica 41-3 2012. Diakses tanggal 25 Februari 2016. http://idb.hr

Lestari, S. T. (2012). Hubungan psikososial dan penyuluhan gizi dengan kepatuhan diet penderita diabetes mellitus tipe 2 rawat jalan di RSUP Fatmawati tahun 2012. Fakultas Kesehatan Masyarakat UI

Odili Valentine, U., Isiboge Paul, D., Eregie Aihanuwa. (2011). Patients' Knowledge of Diabetes mellitus in a Nigerian City. Tropical Journal of Pharmaceutical Research October 2011;10(5): 637-642. Diakses tanggal 22 Februari 2016. http://www.bioline.org.br 